\title{
Faceted Taxonomies for the Performing Arts Domain: The Case of the European Collected Library of Artistic Performance
}

\author{
Irene Scaturro \\ Centro Teatro Ateneo, Performing Arts Research Centre, Sapienza-University of Rome, Via delle \\ Scienze 1,00185 Rome, Italy, <irenescaturro@gmail.com>
}

\begin{abstract}
Irene Scaturro holds a Ph.D. in Digital Technologies and Methodologies applied to the Research on Performing Arts and an M.A. in Theatre Studies, both from University of Rome "La Sapienza." She is involved in the European project ECLAP (co-funded by the ICT-PSP CIP program) and is currently working at Centro Teatro Ateneo, a research centre on performing arts of "La Sapienza." Her research interests include theatre anthropology, knowledge organization, intangible heritage, and audiovisual archiving. She has written about actors' intercultural training, user requirements for digital libraries, knowledge organization, and metadata solutions applied to the performing arts domain.
\end{abstract}

Scaturro, Irene. Faceted Taxonomies for the Performing Arts Domain: The Case of the European Collected Library of Artistic Performance. Knowledge Organization. 40(3), 205-211. 27 references.

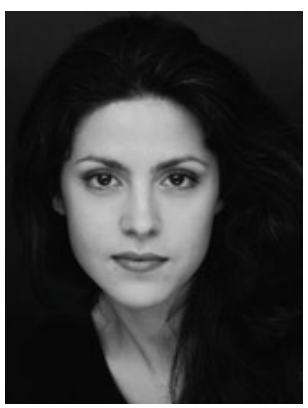

ABSTRACT: The exponential growth of online cultural content presents performing arts heritage institutions with the necessity of adopting new strategies in order to ensure the authentication, utility, and re-usability of both their non-book materials and their textual documents. The case study of a performing arts digital library is described through an interdisciplinary perspective in order to demonstrate the advantages deriving from the application of knowledge organization to the performing arts domain. The article illustrates how controlled vocabularies and faceted taxonomies can improve end-users' access and foster the clustering and the contextualization of performing arts documents. The paper also outlines how shared vocabularies may support transnational dialogue between various cultural repositories and network different types of items. A model for indexing, organizing, and displaying resources within a domain-specific digital library is proposed.

Received 1 February 2013; Accepted 1 February 2013

\subsection{Towards a Performing Arts Digital Library}

The significant growth of both professional and nonprofessional producers of digital cultural content which began towards the end of the twentieth century has led to an exponential increase in online cultural items (Manovich 2010), thus amplifying the risk of losing valuable resources within a mass of irrelevant or unreliable data. In the fields of architecture and fine arts, institutions are aware of the advantages deriving from the application of knowledge organization systems to resource retrieval; as a result, information specialists have already argued in favour of improving access to material culture heritage by using vocabularies (Lanzi and Besser 1999, Harpring 2010). But in the performing arts realm, the advantages deriving from the application of knowledge organization systems to documents and collections are still underesti- mated, and, even if some remarkable attempts were_made in the recent past, they are still restricted to the national level (Scaturro 2013).

Academics often underline that the traditional notion of performance is characterized by contingency, as each show is inscribed within the boundaries of the bic et nunc. Consequently, scholars looking back at the past cannot directly analyze their object of study, but need to collect different documents to reconstruct an idea of the event performed (Marotti 1973). Moreover, it has been repeatedly underlined that performing arts history does not consist exclusively of the reconstruction of the mise-enscène (De Marinis 1995), but also aims at investigating, through any available trace, the artistic process behind performances and the overall contemporaneous sociopolitical, economic, and cultural circumstances in which they took place (De Marinis 1999). 
Therefore, scholars fully recognize the need to collect a plethora of clues by analyzing different document types, ranging from textual materials (such as books, letters, reviews, chronicles) to sketches, paintings, photographs, videos, audio recordings (Marotti 1991), and many other non-book materials. Nevertheless, gathering and clustering these resources is time-consuming and demanding financially, since they are often scattered throughout different countries and repositories. For this reason, the adoption of appropriate knowledge organization systems by performing arts institutions has to be considered of paramount importance in order to organize and network authenticated documents at a transnational level.

The purpose of the ECLAP (European Collected Library of Artistic Performance) project is to collect and link different kinds of performing arts content, with a substantial percentage of non-book materials, from different European repositories and to aggregate them in Europeana, the European digital library. Moreover, ECLAP should make accessible, through its online portal, resources on dance, music, theatre, and performance art, involving users in the creation of possible paths to explore its cultural offer. In order to successfully achieve these results, different issues need to be addressed, including: the standardization of information (Lanzi and Besser 1999), the interoperability of metadata from different institutions and expressed in different languages (Baca 2003), and the identification of users' needs (Nielsen 1990, 1992; Nielsen and Molich 1990). After creating a common metadata schema, which should be appropriate to digital library materials and to its intended endusers, crosswalks can allow effective migration of each institution's dataset to the library schema. Nevertheless, the adoption of a common schema is not sufficient to ensure proper access if it is not populated with standardized data values or if the terms adopted are not selected from a controlled vocabulary (Baca 2003).

Since ECLAP is going to provide about one million items for end-users representing different target groups, it is important to define how these resources are going to be clustered and presented in order to simplify the browsing experience, yet allowing users to rapidly visualize and scan the cultural offer of the portal. Another task to be accomplished is the linking together of diverse kinds of documents that, even though provided by different institutions, are related to the same character, performer, director, topic, etc. Through the case study of the ECLAP library, this paper illustrates how these goals can be achieved by applying knowledge organization to the performing arts domain. Moreover, it describes a process for organizing and displaying resources within a domainspecific digital library. The article will also explain the ad- vantages that can derive, both to the cataloguer and the user, from employing $\mathrm{KO}$ systems to index and present resources.

\subsection{Users versus Experts?}

Among the many aspects to be considered in the design of a library interface, the definition of the most appropriate presentation methods and the display features of the library resources must be considered high priority. In order to investigate user needs and requirements, specific surveys were distributed to a sample of potential users. The questionnaire was divided into four main areas: 1) general information about the users, 2) information about their digital literacy, 3) information about their current usage of performing arts resources, and 4) specific questions regarding their preferred access points.

In the first section of the survey, respondents were asked: a) to define which of the proposed macro categories best describe them, b) to state their occupation/role, and c) to indicate their institutional affiliation. Results indicated that the majority of users are comprised within the Education \& Research category (59.6\% in total), with students from higher practical education representing the largest group $(25.7 \%)$. The rest of the users belong to the Leisure \& Tourism category $(10.9 \%$ in total), composed of performing arts lovers and leisure users, and to the Cultural Heritage Professionals category (25.7\% in total), which is composed of performing arts curators or heritage institution employees $(12.2 \%)$, performing arts practitioners $(2.7 \%)$, and media professionals $(10.8 \%)$. A small percentage of users, who defined themselves as pertaining to the "Other" (4.1\%) macro category, indicated job descriptions that can fit into the macro category Education \& Research $(2.7 \%)$ or Cultural Heritage Professionals $(1.3 \%)$.

The majority $(51.8 \%)$ of the potential users stated that they work or study at a university, while the others mainly work for performing arts institutions, libraries, and archives. Their jobs span a wide range, from digital media advisors to dance researchers to heads of archives (Schuurman et al. 2012). Since the macro category Education and Research represents the largest group of future ECLAP users, the needs of this group were explored further through usability tests based on the open beta version of the portal (Schuurman et al. 2012, Baltussen et al. 2013).

A detailed analysis of the survey and the usability tests results revealed specific user requirements related to browsing content. First of all, users indicated that the browsing experience would greatly benefit from appropriate item clustering (based on shared content features) and a clear and prompt identification of the types of digital objects available on the website. Secondly, users prefer to freely explore different kinds of resources 
choosing among a variety of content types, with a particular interest in performing arts videos, which are the most under-represented on the Web. While some users stated their interest in all time periods $(20 \%)$, the majority indicated a specific preferred time interval, with $38 \%$ of users mostly interested in contemporary content. The survey results clearly show that the majority of the potential ECLAP users is interested in content from all over the world and would like to be able to perform searches at the local, national, transnational, and European levels. Users also declared they would like to be further guided in their research by getting access to content that is clustered by common themes. Participants in the usability tests pointed out that the institution responsible for providing a certain item should be clearly identifiable, in order to ensure the quality and trustworthiness of the collections at a glance. Finally, from the general observation of the usability tests, it emerged that users need to easily visualize the item's copyright status in order to base their choice of content on its specific re-usability possibilities.

In addition to this line of enquiry, existing websites of online performing arts resources were analyzed and evaluated. As their interfaces are usually designed and shaped in order to satisfy customers' needs and simplify website browsing, this analysis was aimed at identifying those characteristics with which users are most familiar (a more detailed study can be found in the document "Classification proposal 2," available at http://www.eclap.eu/drupal). However, some websites present lists of terms too specialized and comprehensive for a non-expert user to begin with, while others completely lack any kind of specific classification. Sometimes websites or thesauri show facets for genres or disciplines whose foci are not homogeneous or are inappropriate: for instance, the "performing arts types" facet may display the focus "video" (which refers to the medium in which the document is expressed), or " $m u$ sical styles" (which should be an autonomous facet). In other cases the approach to performing arts is too simplistic (e.g. "puppet theatre" is often included under the category "children's theatre"). From the evaluation of these websites, it was evident that the vocabularies analyzed were seldom structured from a subject field expert point of view and usually displayed their cultural offer following a customer-oriented perspective.

In a recent article, Hjørland $(2013,12)$ questioned the exclusive adoption of user-centered approaches:

It is not without problems to make educational institutions, libraries, scientific journals, databases, etc. driven by commercial criteria and user demands rather than by scholarly principles and criteria of quality (or, in the case of public libraries, by cultural policies).
However, the author also pointed out that "users always have some kind of pre-knowledge and are positioned somewhere inside the information ecology" (Hjørland $2013,16)$. In this respect, it has to be noted that a substantial part of the potential users for ECLAP can be considered to be domain experts, since they are performing arts scholars, professionals, conservatory or performing arts academy teachers, or university students. Additionally, in order to develop and structure the vocabularies, a Content Board formed by academics from different European countries was consulted.

In this way, the library content was organized taking into account users' desires, which were harmonized with the advice of domain experts. Furthermore, the strategy adopted was revised considering knowledge organization principles and with the contribution of information specialists.

\subsection{Analyzing Content}

While gathering the user responses, another survey was submitted to the partner institutions in order to analyze in depth the mass of resources provided to ECLAP. Results revealed a vast heterogeneity of document types, genres, geographical provenance, historical periods, and performing arts personalities (aggregated results can be found in the document "Content Survey Results," available at http://www.eclap.eu/drupal/).

As the Content Board started analyzing ECLAP resources in different categories, some issues concerning their classification were raised. One problem arose from the vivid academic debate on different genre or time period classification methodologies and different intra- and inter-national definitions, which may change significantly depending on the theoreticians' perspectives.

To solve these classification issues, some well-known reference sources, such as the Oxford Encyclopedia to Theatre and Performing Arts (Kennedy 2003) and the International Encyclopedia of Dance (Cohen 2004), were adopted in order to organize the categories at a general level. To refine specific sub-categories and new (non-traditional) classes, more specialized publications and expert advice (from both scholars and performing arts practitioners) were taken into account.

The categories chosen represent only one of the possible ways to cluster the subject field resources, and they have not been formulated to provide a comprehensive and general description of the performing arts realm. Even if the controlled vocabularies derived from this study can be generalized to similar cases, they have been specifically designed to organize the items provided by ECLAP partners. 


\subsection{Developing a KOS}

The best solution identified to represent the varied content described by partners' questionnaires, while ensuring a user-friendly browsing experience, was the development of faceted taxonomies. In this kind of $\mathrm{KO}$ system, each facet is composed of homogeneous terms called "foci" and structured hierarchically in levels ranging from the most generic lists of terms to the most detailed ones (Gnoli 2008, Vickery 2008). This option was chosen because content partners could define their content in a very specific way through the combination of different facets, whilst taxonomies would reflect the differing levels of users' expertise. In fact, the modulation of degrees of specificity typical of hierarchical structures allows less experienced users to explore the content starting from the most generic terms, while permitting specialists to begin their searches from the deepest level.

On the portal interface, facets will guide different user categories in accessing the resources by scanning pulldown hierarchically-organized lists of foci, which allow faceted browsing (Nudelman 2009). In order to reflect the actual offer of the library, yet avoiding never-ending lists that would complicate the browsing experience, the Content Board discussed both the most appropriate terms to describe ECLAP contents and the degree of specificity of each facet. This committee will also ensure the ongoing development of the controlled vocabularies when new items will be provided to ECLAP.

Taxonomies have been developed in English so that domain experts from each partner institution could translate the vocabularies into their own language, allowing for reliable multilingual browsing and avoiding the risk of error connected to automatic translation.

Facets have been grouped by taking into account the four fundamental questions (What? When? Where? Who?) formulated by Ackoff (1989) to transform data into information.

The first group of facets, answering to the question "what?" are: "Digital Object Type," "Genre," "Language," "Rights," and "Subject."

The first or highest hierarchical level of the "Digital Object Type" facet distinguishes among the four categories adopted by Europeana: Audio, Image, Text, and Video. Once the user selects which category to explore, a second level appears, expressing specifically which kinds of events or documents can be viewed. For example, a user who clicks on the "Video" facet can then browse among following foci:

\footnotetext{
- Conference

- Event

- Performance
}

- Rehearsal

- Speech/Lecture

- Television Program

- Training Session

- Interview

- Workshop

The "Genre" facet, instead, presents three hierarchical levels. Values at the first level were defined through desk research and the analysis of existing websites and thesauri in the Performing Arts. As a reference on performing arts classification in libraries, Sheehy's book Managing Performing Arts Collections in Academic and Public Libraries (1994) was taken into account. As already mentioned, in order to build this facet, other reference sources relating to performing arts were consulted (Cohen 2004, Kennedy 2003, Marranca 2006, Pontremoli 2008, Schechner 2002, Sadie 1980).

The "Language" facet indicates the language of the contents (while the languages of the metadata are automatically detected and translated by the system). In the case of content related to more than one language, the resource will be made accessible through multiple language foci.

The "Rights" facet enables users to view content on the basis of its potential for re-use by showing the kind of copyright licence and the restrictions connected to each resource (e.g., educational, public, no derivative works, share alike). For example, a researcher may want to search only among photographs that can be shown during a symposium, while a director may need to look for archival material that can be used as footage for a documentary.

The "Subject" facet can be used to explore themes which are common to different collections. Its foci may include: artistic movements (e.g., Expressionism, Futurism), performing arts disciplines (e.g., History of Theatre, Physical Training, Voice, Directing), specific issues (e.g., Catharsis, Jealousy, Feminism, Racism), and well-known characters (e.g., Medea, Hamlet, Oedipus, Nora). This will help to create monographs and virtual exhibitions, as well as helping teachers to gather the content needed for their courses. The user community may propose to the Content Board how this facet can be enriched.

The second group of facets, answering the question "when?" are "Historical Period" and "Date." The "Historical Period" facet refers to the period the resource is pointing at, allowing, for instance, access to a contemporary historical reconstruction of a medieval miracle play through the "Middle Ages" focus. Additionally, when a performance shows strong influences from different historical periods, the user will be able to retrieve it through more than one focus. Even though this is a time-related facet, it also implies some information about the main stylistic characteristics of a performance (e.g., a Renais- 
sance work differs dramatically from a Modern era one because of some distinctive features).

On the other hand, the "Date" facet refers to the decade in which the resource was produced (e.g., if the show was produced in 1995, it can be recalled through the “1990-99" facet). This facet gives a synchronic overview of the resources and in conjunction with other facets, it can help to build monographs and specific courses, or highlight similarities and differences among contemporaneous works. For example, performances staged during the same time interval may pertain to different historical periods if they took place in different countries or just show different aesthetic characteristics depending on other factors such as which artistic movement or genre they belong to.

The question "where?" is addressed through the facet "Place," which does not refer to the current location of the physical object, but to the geographical area, country, or region the content is about. As the list of terms chosen for this facet should issue from a specific authority file (Baca 2003), Geonames (http://www.geonames.org/) seemed the most reliable open source authority file for geographical names.

The last group of facets, answering the question "who?" is composed of "Provider" and "Master." The first facet provides information about the institution or person who provided the physical item. Within this facet, a specific focus is dedicated to those resources contributed by the ECLAP community. The "Master" facet's aim, instead, is to cluster content related to important personalities in the performing arts world (who might be singers, dancers, directors, musicians, etc.). This facet is to be linked to the open source VIAF authority file to avoid problems deriving from names which have different spellings and to reconcile art-names.

\subsection{Populating Metadata Elements}

After creating specific metadata fields, one for each facet, the lists of foci were proposed to cataloguers as shared controlled vocabularies to enrich the metadata records and produce tags. This will allow for automatic linking of the facets presented on the portal to the resources in the back office.

Within the system, taxonomies will act as "is-a" (as in the case of the "Genre" facet) or "is-part-of" (as in the case of the "Place" facet) ontologies in order to build relations among terms (Giunchiglia and Maltese, 2010). As a consequence, once the cataloguer has indexed a resource through the deepest level of the taxonomy, the same resource will be automatically indexed with those terms present in the more generic levels. For instance, if a resource is indexed as "Commedia dell'Arte" using a term from the third level of the "Genre" facet, the system will index it under "Comedy" and "Theatre" as well, because these terms (respectively situated in the second and first hierarchical levels of the "Genre" facet) are linked through an "is-a" relation to the "Commedia dell'Arte" focus (i.e., "Commedia dell'Arte" is-a "Comedy," which is-a "Theatre" genre).

The system will also help cataloguers to complete the metadata entry through suggestions and automatic correction during the indexing phase, therefore speeding up the process and avoiding typographical errors. Even though the metadata fields connected to the facets can only be filled in using the controlled vocabularies, cataloguers will still be able to describe each item with free text without restriction using the metadata element "Description."

To avoid the risk of error, these metadata fields should not be translated automatically, unlike the others, but applying the experts' taxonomy translations.

\subsection{Conclusion}

The rise of search as a dominant strategy for finding content is one of the consequences of the dramatic change in people's information environment. Despite massive digitization and the subsequent online availability of all kinds of documents, which allows end-users to cross most geographical barriers, access to theatrical heritage content is still challenging. The proliferation of data in the networked digital setting forged new ways of encountering culture; therefore, to successfully cope with this new landscape, performing arts heritage institutions should adopt specific strategies to ensure the contextualization and recall of their quality resources. A solution consists in applying appropriate $\mathrm{KO}$ systems to organize digital libraries, where authenticated documents can be meaningfully clustered and networked in the same virtual repository.

As the ECLAP case study demonstrates, the adoption of a shared, multilingual controlled vocabulary connected to a faceted taxonomy presents several advantages, since it enriches content descriptions, enhances user experience, and improves the cataloguing process. Content is contextualized effectively through the method described, which meaningfully networks various items which may differ in nature, provenance, and medium. Moreover, since vocabularies were developed following the advice of a multicultural team of experts, the metadata quality benefits from taxonomic consistency, translation accuracy, and the adherence of the chosen terms to the current library collections.

User access is simplified and differentiated according to level of expertise; after getting an overview of the content available, it is possible to browse through the library at different degrees of specificity and to narrow down the amount of items to be viewed through faceted browsing. 
At the same time, retrieval is fostered by multiplying the access points on the basis of user needs. Furthermore, didactic utility for both traditional and e-learning courses is fostered by the possibility of easily aggregating content into transnational monographs and virtual exhibitions portraying, for example, a specific genre, theme, or historical period, or based on a combination of different aspects. Finally, creativity and re-use of content for professional, educational, and leisure purposes are encouraged by the possibility of viewing items on the basis of their copyright licences.

As for cataloguers' working routines, the risk of error in providing metadata records is notably reduced, while the back office process needed to link the taxonomies to the resources is optimized by the usage of the same vocabularies both to present and index resources. The model applied to organize the ECLAP digital library can be generalized to similar projects aimed at indexing and displaying digital artistic heritage, as it guarantees transnational dialogue between cultural repositories of different natures (archives, libraries, museums) and fosters worldwide online use of content. Nevertheless, in order to be effective, faceted taxonomies should be created taking into consideration the specific characteristics of the content available through the digital library, subject knowledge, the advice of information specialists, and the needs of potential users. Moreover, the interoperability and access to the digital library are to be ensured through the adoption of a common metadata schema and multilingual shared controlled vocabularies, while strategies for indexing resources should be developed in conjunction with those regarding content organization and the presentation of the library's cultural offer.

\section{References}

Ackoff, Russell L. 1989. From data to wisdom. Journal of applied systems analysis 16: 3-9.

Baca, Murtha. 2003. Practical issues in applying metadata schemas and controlled vocabularies to cultural heritage information. Cataloging \& classification quarterly 36: 47-55.

Baltussen, Lotte Belice, Bloom, Jaap, Oomen, Johan, Borelli, Maia, Marotti, Ferruccio, Scaturro, Irene, Bellini, Emanuele, Maratea, Katia and Nesi, Paolo. 2013. DE 2.1.2. Revised user requirements and use cases. Available http://bpfe.eclap.eu/eclap/axmedis/c/c17/00000-c17 64b44-f9a3-4338-8150-365ff064aedb/2/ saved-ondb-c1764b44-f9a3-4338-8150-365ff064aedb.pdf.

Cohen, Selma J. 2004. International encyclopedia of dance. Oxford: Oxford University Press.

Hjørland, Birger. 2013. User-based and cognitive approaches to knowledge organization: A theoretical analysis of the research literature. Knowledge organization 40: 11-49.
Giunchiglia, Fausto and Maltese, Vincenzo. 2010. Ontologie leggère a faccette. AIDA informaz̧ioni 28n1/2: 87-95.

Kennedy, Dennis. 2003. The Oxford encyclopedia of theatre and performance. New York: Oxford University Press.

Gnoli, Claudio. 2008. Facets: A fruitful notion in many domains. Axiomathes 18: 127-30.

Harpring, Patricia. 2010. Introduction to controlled vocabularies terminology for art, architecture, and other cultural work. Los Angeles: Getty Publications.

Lanzi, Elisa and Besser, Howard. 1999. Introduction to vocabularies: Enhancing access to cultural heritage information. Los Angeles: Getty Publications.

De Marinis, Marco. 1995. Il divenire della comunicazione audiovisiva. Le memorie audiovisive. La scena in video. I Quaderni della mediateca delle Marche 1/2: 165-72.

De Marinis, Marco. 1999. Capire il teatro. Lineamenti di una nuova teatrologia. Rome: Bulzoni.

Manovich, Lev. 2010. An introduction to cultural analytics. In Changing sceneries changing role - part IV. Keeping your best content and metadata, selected papers from the FIAT media management seminar 15-16 May 2008 Stockholm. Hilversum: Beeld and Geluid, pp. 16-43.

Marranca, Bonnie. 2006. American perfomance 1975-2005. Rome: Bulzoni.

Marotti, Ferruccio. 1973. Note di metodo per lo studio del teatro della regia. Biblioteca teatrale 8: 33-6.

Marotti, Ferruccio. 1991. Elettronica e archiviazione multimediale. Una modesta proposta. In Trezzini, Lamberto ed., Il patrimonio teatrale come bene culturale. Rome: Bulzoni, pp. 49-54.

Nielsen, Jakob and Molich, Rolf. 1990a. Heuristic evaluation of user interfaces. In Proceedings ACM INTERCHI'90 conference, pp. 249-256.

Nielsen, Jakob. 1990b. Paper versus computer implementations as mock-up scenarios for heuristic evaluation. In Proceedings IFIP INTERACT90 third intl. conf. humancomputer interaction, pp. 315-20.

Nielsen, Jakob. 1992. Finding usability problems through heuristic evaluation. In Proceedings ACM CHI'92 conference, pp. 373-80.

Nudelman, Greg. 2009. Best practices for designing faceted search filters. UXmatters. Available http://www. uxmatters.com/mt/archives/2009/09/best-practicesfor-designing-faceted-search-filters.php.

Pontremoli, Alessandro. 2008. La danza. Storia, teoria, estetica nel Novecento, Rome-Bari: Laterza.

Scaturro, Irene. 2013. L'organizzazione della conoscenza e le arti dello spettacolo: fruizione e valorizzazione del documento teatrale. Biblioteca teatrale 98/99: 325-51.

Sadie, Stanley ed. 1980. The new Grove Dictionary of Music and Musicians. London: Macmillan. 
Schechner, Richard. 2002. Performance studies. An introduction. London: Routledge.

Sheehy, Carolyn A. 1994. Managing performing arts collections in academic and public libraries. Westport: Greenwood Press.

Schurmann, Josephine, Eversmann, Peter, Mitolo, Nicola, Nesi, Paolo, Baltussen, Lotte Belice, Borelli, Maia and Scaturro, Irene. 2012. DE 6.2.1 ECLAP specific services.
Available http://bpfe.eclap.eu/eclap/axmedis/4/4e8/ 00000-4e8295a8-507f-42f5-8043-6ce2b1c54e16/3/ saved-on-db-4e8295a8-507f-42f5-8043-6ce2b1c54e16. pdf.

Vickery, Brian. 2008. Faceted classification for the Web. Axiomathes 18: 145-60. 


\title{
KNOWLEDGE ORGANIZATION
}

\author{
Official Bi-Monthly Journal of the International Society for Knowledge Organization
}

ISSN $0943-7444$

International Journal devoted to Concept Theory, Classification, Indexing and Knowledge Representation

\section{Publisher}

ERGON-Verlag GmbH, Keesburgstr. 11, D-97074 Würzburg Phone: +49(0)931 280084; FAX +49 (0)931 282872

E-mail: service@ergon-verlag.de; http://www.ergon-verlag.de

\section{Editor-in-chief (Editorial office)}

Dr. Richard P. SMIRAGLIA (Editor-in-Chief), School of Information Studies, University of Wisconsin, Milwaukee, Northwest Quad Building B, 2025 E Newport St., Milwaukee, WI 53211 USA. E-mail: smiragli@uwm.edu

\section{Instructions for Authors}

Manuscripts should be submitted electronically (in Word format) in English only via email to the editor-in chief and should be accompanied by an indicative abstract of 150 to 200 words. Manuscripts of articles should fall within the range 6,000-10,000 words. Longer manuscripts will be considered on consultation with the editor-in-chief.

A separate title page should include the article title and the author's name, postal address, and E-mail address, if available. Only the title of the article should appear on the first page of the text.

To protect anonymity, the author's name should not appear on the manuscript, and all references in the body of the text and in footnotes that might identify the author to the reviewer should be removed and cited on a separate page.

Criteria for acceptance will be appropriateness to the field of the journal (see Scope and Aims), taking into account the merit of the contents and presentation. The manuscript should be concise and should conform as much as possible to professional standards of English usage and grammar. Manuscripts are received with the understanding that they have not been previously published, are not being submitted for publication elsewhere, and that if the work received official sponsorship, it has been duly released for publication. Submissions are refereed, and authors will usually be notified within 6 to 10 weeks.

The text should be structured by numbered subheadings. It should contain an introduction, giving an overview and stating the purpose, a main body, describing in sufficient detail the materials or methods used and the results or systems developed, and a conclusion or summary.

Footnotes are accepted only in rare cases and should be limited in number; all narration should be included in the text of the article. Paragraphs should include a topic sentence and some developed narrative; a typical paragraph has several sentences. Italics may not be used for emphasis. Em-dashes should not be used as substitutes for commas.

Italics should not be used for emphasis. Em-dashes should be used as substitutes for commas. Paragraphs should include a topic sentence and some developed narrative. A typical paragraph has several sentences.

Reference citations within the text should have the following form: (Author year). For example, (Jones 1990). Specific page numbers are required for quoted material, e.g. (Jones 1990, 100). A citation with two authors would read (Jones and Smith, 1990); three or more authors would be: (Jones et al., 1990). When the author is mentioned in the text, only the date and optional page number should appear in parenthesis e.g. According to Jones (1990), ...
References should be listed alphabetically by author at the end of the article. Author names should be given as found in the sources (not abbreviated). Journal titles should not be abbreviated. Multiple citations to works by the same author should be listed chronologically and should each include the author's name. Articles appearing in the same year should have the following format: "Jones 2005a, Jones 2005b, etc." Issue numbers are given only when a journal volume is not throughpaginated.

Examples:

Dahlberg, Ingetraut. 1978. A referent-oriented, analytical concept theory for INTERCONCEPT. International classification 5: 142-51.

Howarth, Lynne C. 2003. Designing a common namespace for searching metadata-enabled knowledge repositories: an international perspective. Cataloging \& classification quarterly 37n1/2: 173-85.

Pogorelec, Andrej and Šauperl, Alenka. 2006. The alternative model of classification of belles-lettres in libraries. Knowledge organization 33: 204-14.

Schallier, Wouter. 2004. On the razor's edge: between local and overall needs in knowledge organization. In McIlwaine, Ia C. ed., Knowledge organization and the global information society: Proceedings of the Eighth International ISKO Conference 13-16 July 2004 London, UK. Advances in knowledge organization 9. Würzburg: Ergon Verlag, pp. 269-74.

Smiraglia, Richard P. 2001. The nature of 'a work': implications for the organization of knowledge. Lanham, Md.: Scarecrow.

Smiraglia, Richard P. 2005. Instantiation: Toward a theory. In Vaughan, Liwen, ed. Data, information, and knowledge in a networked world; Annual conference of the Canadian Association for Information Science ... London, Ontario, June 2-4 2005. Available http://www.cais-acsi.ca/2005proceedings.htm.

Illustrations should be kept to a necessary minimum and should be embedded within the document. Photographs (including color and halftone) should be scanned with a minimum resolution of $600 \mathrm{dpi}$ and saved as .jpg files. Tables and figures should be embedded within the document. Tables should contain a number and title at the bottom, and all columns and rows should have headings. All illustrations should be cited in the text as Figure 1, Figure 2, etc. or Table 1, Table 2, etc.

The entire manuscript should be double-spaced, including notes and references.

Upon acceptance of a manuscript for publication, authors must provide a wallet-size photo and a one-paragraph biographical sketch (fewer than 100 words). The photograph should be scanned with a minimum resolution of $600 \mathrm{dpi}$ and saved as a .jpg file.

\section{Advertising}

Responsible for advertising: ERGON-Verlag GmbH, Keesburgstr. 11, 97074 Würzburg (Germany).

(C) 2013 by ERGON-Verlag GmbH.

All Rights reserved.

KO is published bi-monthly by ERGON-Verlag GmbH.

- The price for the print version is $€ 229,00 /$ ann. including airmail delivery.

- The price for the print version plus access to the online version (PDF) is $€ 258,00 /$ ann. including airmail delivery. 


\section{$\mathrm{KO}$}

\section{KNOWLEDGE ORGANIZATION}

Official Bi-Monthly Journal of the International Society for Knowledge Organization

ISSN $0943-7444$

International Journal devoted to Concept Theory, Classification, Indexing and Knowledge Representation

\section{Scope}

The more scientific data is generated in the impetuous present times, the more ordering energy needs to be expended to control these data in a retrievable fashion. With the abundance of knowledge now available the questions of new solutions to the ordering problem and thus of improved classification systems, methods and procedures have acquired unforeseen significance. For many years now they have been the focus of interest of information scientists the world over.

Until recently, the special literature relevant to classification was published in piecemeal fashion, scattered over the numerous technical journals serving the experts of the various fields such as:

\author{
philosophy and science of science \\ science policy and science organization \\ mathematics, statistics and computer science \\ library and information science \\ archivistics and museology \\ journalism and communication science \\ industrial products and commodity science \\ terminology, lexicography and linguistics
}

Beginning in 1974, KNOWLEDGE ORGANIZATION (formerly INTERNATIONAL CLASSIFICATION) has been serving as a common platform for the discussion of both theoretical background questions and practical application problems in many areas of concern. In each issue experts from many countries comment on questions of an adequate structuring and construction of ordering systems and on the problems of their use in opening the information contents of new literature, of data collections and survey, of tabular works and of other objects of scientific interest. Their contributions have been concerned with

(1) clarifying the theoretical foundations (general ordering theory/ science, theoretical bases of classification, data analysis and reduction)

(2) describing practical operations connected with indexing/classification, as well as applications of classification systems and thesauri, manual and machine indexing

(3) tracing the history of classification knowledge and methodology

(4) discussing questions of education and training in classification

(5) concerning themselves with the problems of terminology in general and with respect to special fields.

\section{Aims}

Thus, KNOWLEDGE ORGANIZATION is a forum for all those interested in the organization of knowledge on a universal or a domainspecific scale, using concept-analytical or concept-synthetical approaches, as well as quantitative and qualitative methodologies. KNOWLEDGE ORGANIZATION also addresses the intellectual and automatic compilation and use of classification systems and thesauri in all fields of knowledge, with special attention being given to the problems of terminology.

KNOWLEDGE ORGANIZATION publishes original articles, reports on conferences and similar communications, as well as book reviews, letters to the editor, and an extensive annotated bibliography of recent classification and indexing literature.

KNOWLEDGE ORGANIZATION should therefore be available at every university and research library of every country, at every information center, at colleges and schools of library and information science, in the hands of everybody interested in the fields mentioned above and thus also at every office for updating information on any topic related to the problems of order in our information-flooded times.

KNOWLEDGE ORGANIZATION was founded in 1973 by an international group of scholars with a consulting board of editors representing the world's regions, the special classification fields, and the subject areas involved. From 1974-1980 it was published by K.G. Saur Verlag, München. Back issues of 1978-1992 are available from ERGONVerlag, too.

As of 1989, KNOWLEDGE ORGANIZATION has become the official organ of the INTERNATIONAL SOCIETY FOR KNOWLEDGE ORGANIZATION (ISKO) and is included for every ISKOmember, personal or institutional in the membership fee (US \$ 55/ US \$110).

Rates: From 2013 on for 6 issues/ann. (including indexes) $€ 229,00$ (forwarding costs included) for the print version resp. $€ 258,00$ for the print version plus access to the online version (PDF). Membership rates see above.

ERGON-Verlag GmbH, Keesburgstr. 11, D-97074 Würzburg; Phone: +49 (0)931 280084; FAX +49 (0)931 282872; E-mail: service@ergon-verlag.de; http://www.ergon-verlag.de

Founded under the title International Classification in 1974 by Dr. Ingetraut Dahlberg, the founding president of ISKO. Dr. Dahlberg served as the journal's editor from 1974 to 1997 , and as its publisher (Indeks Verlag of Frankfurt) from 1981 to 1997.

The contents of the journal are indexed and abstracted in Social Sciences Citation Index, Web of Science, Information Science Abstracts, INSPEC, Library and Information Science Abstracts (LISA), Library, Information Science \& Technology Abstracts (EBSCO), Library Literature and Information Science (Wilson), PASCAL, Referatimyi Zhurnal Informatika, and Sociological Abstracts. 